\title{
Arsenic Levels in the Environment and Foods Around Kisumu, Kenya
}

\author{
Anselimo O. Makokha ${ }^{1, *}$, Peter K. Kinyanjui ${ }^{1}$, Happy S. Magoha ${ }^{2}$, Leonard R. Mghweno ${ }^{3}$, \\ Amina Nakajugo ${ }^{4}$ and John M. Wekesa ${ }^{1}$ \\ ${ }^{1}$ Jomo Kenyatta University of Agriculture and Technology, Dept of Food Science, P.O. Box 62,000 - 00200, Nairobi, Kenya \\ ${ }^{2}$ Open University of Tanzania, Faculty of Science, Technology and Environmental Studies, P.O. Box 23409, Dar es Sa- \\ laam, Tanzania \\ ${ }^{3}$ Bugema University, Department of Education, P.O.Box 6529, Kampala, Uganda \\ ${ }^{4}$ Islamic University of Uganda, Faculty of Arts and Social Sciences, P.O. Box 2555, Mbale, Uganda
}

\begin{abstract}
The objective of this study was to determine the level of arsenic in the environment and in foods consumed around Kisumu, and compare these levels with the recommended WHO maximum limits. Arsenic was determined in water samples from Lake Victoria, River Nyamasaria, tap water as well as in the soil samples. It was also determined in staple foods including maize, beans, fish and vegetables. Arsenic content in the samples was determined using Atomic Absorption Spectrophotometry. The results showed that arsenic content in the water and soil ranged from 0.00 to 8.30 $\mathrm{ng} / 100 \mathrm{ml}$ and 12.39 to $24.36 \mu \mathrm{g} / 100 \mathrm{~g}$, respectively, and the mean arsenic levels in all water and soil samples were within the safe WHO limits for arsenic. The arsenic content in the maize and bean samples ranged from 5.21 to $7.03 \mu \mathrm{g} / 100 \mathrm{~g}$. The arsenic content in the vegetables and fish ranged from 2.89 to 7.34 and 4.31 to $7.66 \mu \mathrm{g} / 100 \mathrm{~g}$, respectively. The arsenic content in all the food samples were also within the safe WHO arsenic limits. However, there were variations in arsenic contents between the species of fish studied. The arsenic content was significantly higher in soil samples in comparison to water samples $(\mathrm{p}<0.05)$. Overall the arsenic levels in all the food, water and soil samples were within the maximum WHO safe limits. It is recommended that continuous monitoring of arsenic levels of water, soil and foods be put in place since there could be seasonal variations in their levels.
\end{abstract}

Keywords: Arsenic, environment, foods, WHO limits.

\section{INTRODUCTION}

Heavy metal toxicity represents a significant public health problem world wide. If unrecognized or inappropriately treated, heavy metal toxicity can result in significant morbidity and mortality [1]. Various regulatory bodies around the world strictly regulate the maximum concentrations of heavy metal contaminants in foodstuffs, drugs and cosmetics. Most regulations place maximum limits for these trace metal contaminants in foods and water [2]. Generally, children are more susceptible to the toxic effects of the heavy metals and are more prone to accidental exposures.

The symptoms of chronic arsenic poisoning usually begin half an hour after exposure. They include stomach pain and a tightness of the throat. Vomiting and intense diarrhoea quickly follow. The output of urine is characteristically decreased. Death from total cardiovascular collapse usually results within a few days. Deaths that occur up to 14 days after acute arsenic poisoning are usually caused by nephritis [3]. In chronic arsenic poisoning, diarrhoea and vomiting

\footnotetext{
*Address correspondence to this author at the Jomo Kenyatta University of Agriculture and Technology, Kenya; Tel: +254 713 817436?;

E-mail: anmakokha@yahoo.com
}

occur, but these are less pronounced than they are in cases of acute arsenic poisoning. Chronic toxicity is also associated with skin hyperpigmentation, muscle weakness, peripheral neuropathy, excessive sweating, liver damage, delirium, encephalopathy and cancers of the oral cavity, skin, lungs, colon, bladder, and kidney $[4,5]$.

The objective of this study was to determine the arsenic levels in the environment (water and soil) and foods around Kisumu City in Kenya, and compare these levels with the recommended WHO maximum levels. Kisumu City is the headquarters of Nyanza Province, Kenya, on the northeastern shore of Lake Victoria. It is the commercial, industrial, and transportation centre of western Kenya, serving a hinterland populated by almost four million people. It is an important link in the Lake Victoria-Mombasa trade because of its water and rail connections. This has led to a high population density in the town, which results in heavy vehicle population, and other forms of human activities that have the potential to increase pollution.

\section{METHODOLOGY}

\section{Study Design and Site}

The study was carried out within a 10 kilometre radius in and around Kisumu City in 2009. It was a laboratory based 
study where samples of water, soil and food were obtained from around Kisumu and analyzed for their arsenic content.

\section{Samples}

Water samples were obtained from the Lake Victoria, river Nyamasaria, and taps. The sampling sites for water were purposively chosen. The lake water was sampled at the Dunga Beach and Tilapia Beach landing sites. At each sampling point, five samples of $500 \mathrm{ml}$ were collected. The sampling was done at the shore and at 200 metres inshore at a depth of $30 \mathrm{~cm}$. The river water was sampled from River Nyamasaria near the Nyamasaria Bridge which is on the Nairobi-Kisumu highway. Five river water samples of 500 $\mathrm{ml}$ each were collected. The tap water was randomly sampled from five sampling points and each sample size was $500 \mathrm{ml}$.

Soils were sampled from purposively selected sampling points from where grid sampling was adopted to take three $500 \mathrm{~g}$ samples. The samples were collected at the depth of 0 $15 \mathrm{~cm}$ [2]. The samples were obtained from among other areas, the highway and also $2 \mathrm{~km}$ into the interior away from the highway. The sampling was done as per the IAEA protocols for soil sampling [2].

For food samples, $500 \mathrm{~g}$ each of dry maize and dry beans, among the main staple foods in the region, were purchased from five randomly selected vendors in the Kisumu open air market. Similarly, $500 \mathrm{~g}$ samples of various vegetables from around Kisumu. The vegetables purchased included Spiderplant (akeyo/deck) (Cleome gyanadra L), Spinach (Spinacia oleracea), Kales (Brasicca oleracea), Black nightshade (Solanum nigrum), Amaranth (Amaranth amaranth) and Cow peas (Vigna unguiculata L). Fish of different species were purchased at the Dunga and Tilapia landing sites on Lake Victoria and at the Kisumu Open Air Market. This was done early in the morning as the fishermen landed after overnight fishing. The fish varieties analyzed included Nile tilapia (Oreochromis niloticus (L)), Nile perch (Lates (lates) niloticus (L)), Butter catfish (Schilbe intermedius (Ruppell)), Migori haplo (Haprochromis species) and Dagaa (Lake Victoria sardine (Rastrineobola argentea (Pellegrin)). Three samples of each fish species were purchased from randomly chosen fishermen at each of the two landing sites. Dry dagaa samples $(500 \mathrm{~g} \mathrm{x} 3)$ were purchased from the Kisumu open air market.

\section{Sample Handling and Preparation}

Immediately after sampling, $5 \mathrm{ml}$ of concentrated $\mathrm{HCl}$ was added to the water samples to stabilize them [6]. They were then transported to the laboratory and kept under refrigeration conditions awaiting analysis.

For soil samples, they were transported to the laboratory in the sample bottles. They were then air-dried, ground, and screened to pass through a $0.5 \mathrm{~mm}$ sieve and stored in plastic jars awaiting analysis [7].

The food samples, other than fish were similarly transported in the sample bottles to the laboratory, where they had the adhering soil particles removed. The samples were cleared of adhering soil particles, washed three times with de-ionized water and $0.05 \mathrm{M} \mathrm{HCl}$, and then rinsed with de- ionized water three times to ensure dislodging and removal of dust particles [8]. They were then dried in a fan-forced oven at $60 \pm 5{ }^{\circ} \mathrm{C}$ for 48 hours, ground using a stainless steel grinder, sifted through a $0.2-\mathrm{mm}$ sieve, and stored in plastic jars to await analysis [7]. The maize and bean samples were ground and dried at $100{ }^{\circ} \mathrm{C}$ for 10 hours prior to analysis.

\section{Arsenic Determination}

The arsenic content in the samples was determined using a Shimadzu Atomic Absorption Spectrophotometer (AAS) Model AA-6200 [9]. For each water sample, $100 \mathrm{ml}$ of the sample was put into a $250 \mathrm{ml}$ beaker and placed on the hot plate. The water was brought to boil and while about to boil, $2 \mathrm{ml}$ of nitric acid-water mixture (50:50) and $10 \mathrm{ml}$ hydrochloric acid-water mixture (50:50) were added. The samples were then evaporated until the mixture reduced to approximately $25 \mathrm{ml}$. The $25 \mathrm{ml}$ residues were then transferred into $100 \mathrm{ml}$ volumetric flasks and topped up to the mark with distilled water [6].

For the soil and food samples, three $1 \mathrm{~g}$ replicates of each solid sample were analyzed as per the AOAC method for arsenic determination [7]. The samples were treated with $5 \mathrm{ml}$ of a mixture of nitric acid, sulphuric acid and perchloric acid in the ratio of $6: 3: 1$. They were allowed to stand for five minutes after shaking thoroughly [9]. They were then digested on the hot plate starting at $70{ }^{\circ} \mathrm{C}$ through to $120{ }^{\circ} \mathrm{C}$ until the volume reduced to approximately $1 \mathrm{ml}$ and floating suspended white fumes of $\mathrm{SO}_{3}$ were clearly observed. The samples were then allowed to cool to room temperature and approximately $20 \mathrm{ml}$ of $5 \% \mathrm{HCl}$ acid solution added. The samples were then heated on the hotplate at approximately $75{ }^{\circ} \mathrm{C}$ for 15 minutes and then allowed to cool. The samples were then filtered through Whatman Filter Paper number 42 into a $100 \mathrm{ml}$ volumetric flask and topped up using $5 \% \mathrm{HCl}$. A blank was also prepared in the same way $[8,10]$.

The arsenic content in the samples was then determined using a Shimadzu AAS Model AA-6200 [9,11]. The detection limit of the spectrophotometer was $0.01 \mu \mathrm{g} / 100 \mathrm{~g} / \mathrm{ml}$. This was confirmed by series dilutions made from arsenic standard.

\section{Data Quality Assurance}

To enhance quality assurance of the data, commercial arsenic standards were used as reference (Wako Pure Chemical Industries Ltd., Japan). Further, each sample was analysed in triplicate. A minimum of three samples, each $500 \mathrm{~g} / \mathrm{ml}$, had been obtained to represent each one sample.

\section{Analysis of Data}

Statistical analysis of the data was done using SAS (SAS version 9.2) to compare the arsenic concentrations in the different samples of foods, soils and water. Both qualitative and quantitative data analysis was done. Descriptive indices including means, range and standard error were used to describe the resulting data [12]. Results of analysis were also compared with the World Health Organization (WHO) maximum permissible concentrations (MPC) for arsenic safety in human beings $[13,14]$. 
Table 1. Arsenic Content in Water (ng/100 g)

\begin{tabular}{|l|c|c|c|}
\hline Sample & Mean & Minimum & Maximum. \\
\hline \hline Dunga Beach, 200 m inshore & & 1.60 & 2.70 \\
\hline Tap water & $2.0 \pm 0.10^{\mathrm{d}}$ & 0.00 & 0.00 \\
\hline River Nyamasaria & $0.00^{\mathrm{e}}$ & 0.00 & 3.90 \\
\hline Tilapia Beach, 200m inshore & $1.7 \pm 0.60^{\mathrm{d}}$ & 2.70 & 5.80 \\
\hline Tilapia Beach shoreline & $4.2 \pm 0.50^{\mathrm{c}}$ & 9.10 & 16.80 \\
\hline Dunga shoreline & $13.1 \pm 1.10^{\mathrm{a}}$ & 1.30 & 11.30 \\
\hline WHO minimum limits & $8.30 \pm 1.10^{\mathrm{b}}$ & & \\
\hline
\end{tabular}

Each value is a mean \pm SE of three analyses each done in triplicates.

Means within columns followed by different letters are significantly different $(\mathrm{p}<0.05)$ from each other.

Table 2. Arsenic Content in Soils ( $\mu \mathrm{g} / 100 \mathrm{~g})$

\begin{tabular}{|l|c|c|c|}
\hline Sample & Mean & Minimum & Maximum \\
\hline \hline Dunga Beach & & 11.1 & 14 \\
\hline River Nyamasaria & $12.39 \pm 0.65^{\mathrm{c}}$ & 23.1 & 26.6 \\
\hline Tilapia Beach & $24.36 \pm 0.50^{\mathrm{a}}$ & 13.2 & 17.1 \\
\hline Roadside & $15.92 \pm 1.46^{\mathrm{bc}}$ & 10.3 & 24.3 \\
\hline 2 km from the roadside & $19.01 \pm 0.53^{\mathrm{b}}$ & 9.25 & 16.2 \\
\hline Dunga Beach & $12.39 \pm 0.06^{\mathrm{c}}$ & 11.1 & 14.0 \\
\hline WHO limit & $12.39 \pm 0.65^{\mathrm{c}}$ & & \\
\hline
\end{tabular}

Each value is a mean $\pm \mathrm{SE}$ of three analyses done in triplicates.

Means within columns followed by different letters are significantly different $(\mathrm{p}<0.05)$ from each other.

\section{RESULTS}

\section{Arsenic Content in Water}

The results of arsenic content in water from Kisumu region are shown in Table $\mathbf{1}$. The arsenic content of water from the Tilapia Beach shoreline was significantly higher $(\mathrm{p}<$ $0.05)$ than the content from the other water samples. The tap water did not contain any detectable amounts of arsenic. This could be attributed to the water treatment process where much of the arsenic could have been removed together with the floccules during the sedimentation step. It was also noted that the arsenic content in the waters from the beach and the lake inshore were significantly different $(\mathrm{p}<0.05)$ at the two beaches (Tilapia and Dunga). The shoreline waters had significantly higher $(\mathrm{p}<0.05)$ levels of arsenic than the inshore waters. This indicates that there is a reduction in arsenic content in the lake waters with increasing distance from the shoreline. This suggests that anthropogenic activity may contribute some arsenic pollution at the shorelines.

It was also noted that the arsenic content in the River Nyamasaria waters was not significantly different from the arsenic content of the Lake Victoria shoreline water from the two beaches (Dunga and Tilapia). This could be attributed to the fact that the water from both sources had been exposed to human activities. The water from the Tilapia beach shoreline had significantly higher $(\mathrm{p}<0.05)$ arsenic content than the
Dunga beach shoreline waters. WHO has recommended 10 parts per billion $(1 \mu \mathrm{g} / 100 \mathrm{ml})$ as the limit for arsenic in drinking water [14]. From the results obtained, all the water sources analyzed were within this limit ranging from 0.00 to $13.1 \mathrm{ng} / 100 \mathrm{ml}(0.00$ to $0.013 \mu \mathrm{g} / 100 \mathrm{ml})$

\section{Arsenic Content in Soil}

The arsenic content of soils sourced from Kisumu is shown in Table 2. From the results obtained from this study, soil from R. Nyamasaria was found to have significantly higher $(p<0.05)$ levels of arsenic as compared to the rest of the soil samples. This could be due to higher anthropogenic activities around the river since there was bathing and washing of clothes taking place there.

Arsenic content in the Dunga shoreline soil and that from $2 \mathrm{~km}$ from the highway were significantly lower $(\mathrm{p}<0.05)$ than that from the roadside and river Nyamasaria soils. This may be attributed to such soils experiencing low level of anthropogenic activities. It was also noted that there was no significant difference $(p>0.05)$ in the arsenic content in the soils from the two beaches (Dunga and Tilapia) which is an indicator of similarities in human activities at the two beaches. The arsenic content in the roadside soils was also not significantly different $(\mathrm{p}>0.05)$ from that of the Tilapia beach soils. 
Table 3. Arsenic Content in Dry Maize and Beans ( $\mu \mathrm{g} / 100 \mathrm{~g})$

\begin{tabular}{|l|c|c|}
\hline Sample & Mean & \multicolumn{2}{|c|}{ Range } & Minimum \\
\hline \hline Maize & $7.03 \pm 0.4^{\mathrm{a}}$ & 6.08 \\
\hline Green/yellow beans & $5.21 \pm 0.7^{\mathrm{c}}$ & 4.91 \\
\hline Red/white beans & $6.31 \pm 0.9^{\mathrm{b}}$ & 5.61 \\
\hline WHO limit & 10 & 7.01 \\
\hline
\end{tabular}

Each value is a mean \pm SE of three analyses done in triplicates.

Means within columns followed by different letters are significantly different $(\mathrm{p}<0.05)$ from each other.

Table 4. Arsenic Content in Leafy Vegetables ( $\mu \mathrm{g} / 100 \mathrm{~g})$

\begin{tabular}{|c|c|c|c|}
\hline Sample & Mean & \multicolumn{2}{|c|}{ Range } \\
\hline & & Minimum & Maximum \\
\hline Spiderplant & $3.94 \pm 0.08^{\mathrm{de}}$ & 3.64 & 4.25 \\
\hline Tomatoes & $4.56 \pm 0.06^{\mathrm{cd}}$ & 4.39 & 4.67 \\
\hline Black nightshade & $7.34 \pm 0.07^{\mathrm{a}}$ & 7.16 & 7.50 \\
\hline Onions & $2.89 \pm 0.10^{\mathrm{e}}$ & 2.40 & 3.39 \\
\hline Amaranthus & $5.96 \pm 0.32^{\mathrm{ab}}$ & 5.07 & 7.28 \\
\hline Cow peas leaves & $3.85 \pm 0.16^{\mathrm{de}}$ & 3.59 & 4.29 \\
\hline Kales & $6.96 \pm 0.09^{\mathrm{a}}$ & 6.77 & 7.20 \\
\hline WHO limit & 10 & & \\
\hline
\end{tabular}

Each value is a mean \pm SE of three analyses done in triplicates.

Means within columns followed by different letters are significantly different $(\mathrm{p}<0.05)$ from each other.

Table 5. Arsenic Content in Fish $(\mu \mathrm{g} / 100 \mathrm{~g})$

\begin{tabular}{|l|c|c|}
\hline \multicolumn{1}{|c|}{ Sample } & Mean & Mange \\
\hline \hline Dry sardines & & Maximum \\
\hline Fresh sardines & $7.62 \pm 0.27^{\mathrm{a}}$ & 7.10 \\
\hline Nile perch & $5.12 \pm 0.38^{\mathrm{bc}}$ & 4.27 \\
\hline Tilapia (medium) & $3.92 \pm 0.42^{\mathrm{d}}$ & 3.11 \\
\hline WHO & $5.44 \pm 0.49^{\mathrm{bc}}$ & 4.59 \\
\hline
\end{tabular}

Each value is a mean \pm SE of three analyses done in triplicates.

Means within columns followed by different letters are significantly different $(\mathrm{p}<0.05)$ from each other.

The WHO limit for arsenic in agricultural soils is 50 $\mu \mathrm{g} / 100 \mathrm{~g}$ [14]. This limit was not exceeded by any of the soil samples analyzed.

\section{Arsenic Content in Maize and Beans}

Arsenic contents of maize and beans are shown in Table 3. From the results obtained from this study, maize had significantly $(p<0.05)$ higher levels of arsenic than beans. Among the two varieties of beans analyzed, there was a significant difference $(\mathrm{p}<0.05)$ in the amount of arsenic.

The WHO limit set for cereals is $10 \mu \mathrm{g} / 100 \mathrm{~g}$ (WHO, 2003) which was not exceeded by the maize purchased from Kisumu market. The WHO limit set for pulses is also 10 $\mu \mathrm{g} / 100 \mathrm{~g}$ (WHO, 2003) which was also not exceeded by the two varieties of beans in this study.

\section{Arsenic Content in Vegetables}

Arsenic content in the vegetables commonly consumed around Kisumu are shown in Table 4. The arsenic level ranged from a minimum of $2.40 \mu \mathrm{g} / 100 \mathrm{~g}$ in amaranthus leaves to a maximum of $7.50 \mu \mathrm{g} / 100 \mathrm{~g}$ in black nightshade. From the results obtained, black nightshade had significantly higher $(\mathrm{p}<0.05)$ arsenic content than the rest of the vegetables analyzed. The WHO limits for arsenic in fruits and vegetables is $10 \mu \mathrm{g} / 100 \mathrm{~g}$ [14]. This limit was not exceeded by any of the fruits and vegetables analyzed in the current study.

\section{Arsenic Content in Fish}

Arsenic content in fish samples of the commonly consumed fish around Kisumu is shown in Table 5. The levels ranged from a minimum of 3.92 in Nile perch to a maximum 
of 8.78 in dry sardines. The dry sardines (dagaa) had significantly higher levels $(\mathrm{p}<0.05)$ of arsenic as compared to nile perch and tilapia. The fresh sardines had significantly lower levels of arsenic $(\mathrm{p}<0.05)$ as compared to the dried sardines' sample. This could be attributed to the concentration of the arsenic during drying process. The difference between the fresh and dry sardines could also be attributed to exposure to anthropological contamination during drying and display in the market.

The WHO limit for arsenic in fish is $10 \mu \mathrm{g} / 100 \mathrm{~g}$ [14]. The arsenic levels in all the fish samples did not exceed this limit.

The WHO limit for arsenic in fish is $10 \mu \mathrm{g} / 100 \mathrm{~g}$ [14]. This limit was not exceeded by any of the fish samples analyzed in the current study.

\section{DISCUSSION}

The physical, chemical and biological processes that occur in an aquatic environment often affect the inorganic elements and heavy metal concentrations $[15,16]$. Human activities, which control these processes, have been reported to increase the concentration of metals in many of the natural water systems [17]. In addition, conditions in the catchments and lake are important for the mobility and availability of metals in the water. Rivers and lakes are exposed to atmospheric deposition of anthropogenicaly derived trace elements. This can create harmful effects on the environment and human health due to their toxicity and bioaccumulation in various environmental compartments [3, 18]. Fortunately, the arsenic levels in the water bodies around Kisumu, including Lake Victoria, were within the maximum WHO safe limits. However, the observation that there were significant differences in the arsenic levels in the water samples suggest that anthropogenic activities do have some effect on these levels.

In soils contaminated through anthropogenic activity, arsenic contents may be high, exceeding $50 \mathrm{mg} / \mathrm{kg}$ [19]. This was not the case in this study, despite the fact that some of the sites where the soil samples were obtained had high vehicular traffic as well as a relatively high level of other anthropogenic activities. The combustion of petroleum products has been reported to emit some arsenic [20].

In a study in Bangladesh, concentration of arsenic in the irrigated soils varied from 0.32 to $2.75 \mathrm{mg} / 100 \mathrm{~g}$. On the other hand, in the areas where irrigation-water did not contain arsenic, the soil arsenic levels varied from 0.01 to 0.28 $\mathrm{mg} / 100 \mathrm{~g}$ [21]. The concentrations of arsenic in the soils in the current study $(0.012$ to $0.024 \mathrm{mg} / 100 \mathrm{~g})$ were much lower than those reported in the Bangladesh study.

Dietary arsenic represents the major source of arsenic exposure for most of the general population. The actual total arsenic concentrations in foodstuffs from various countries vary widely depending on the food type, growing conditions (type of soil, water, geochemical activity, use of arsenical pesticides) and processing techniques [22]. Arsenic content of $20 \mu \mathrm{g} / 100 \mathrm{~g}$ has been reported in the cereals consumed in some of the USA diets [23]. The findings of this study (5.2 to $7.0 \mu \mathrm{g} / 100 \mathrm{~g}$ ) indicated a comparatively much lower level of total arsenic in the maize sold in Kisumu. In the same USA study, the total arsenic levels in pulses were reported to be $20 \mu \mathrm{g} / 100 \mathrm{~g}$ [23]. This is also much higher than the arsenic levels observed in the beans in this study. In another study in Bangladesh, the level of arsenic in both cereals and pulses was established as $20 \mu \mathrm{g} / 100 \mathrm{~g}$ [22], which is also much higher than the levels found in this study. Maize and beans are among the main staple foods around Kisumu [24].

In a study by Naidu [25], arsenic levels of less than 1.0 $\mu \mathrm{g} / 100 \mathrm{~g}$ were observed in vegetables. This levels were much lower than those observed in this study. In another study in Bangladesh, the arsenic content in leafy vegetables was 2.8 to $7.0 \mu \mathrm{g} / 100 \mathrm{~g}$ [21]. In the same study the arsenic content of the onions was found to be $5 \mu \mathrm{g} / 100 \mathrm{~g}$ which was similar to the arsenic content of onions in this study.

Several studies have shown that arsenic content in plants varied considerably with type of plants, type of soil, and arsenic content of irrigation-water. Generally, the highest concentrations of arsenic were always recorded in plant-roots, and this may be attributed to contamination from fine colloidal particles [26-28].

In a study in the USA arsenic levels of $110 \mu \mathrm{g} / 100 \mathrm{~g}$ in fish were reported [23]. This was much higher than the levels of arsenic observed in this study.

\section{CONCLUSIONS}

In conclusion, the main findings of the study is that arsenic content in all water and soil samples from all the sites in Kisumu ranged from 0.00 to $8.30 \mathrm{ng} / 100 \mathrm{ml}$ and 12.39 to $24.36 \mu \mathrm{g} / 100 \mathrm{~g}$, respectively, and were within the WHO maximum safe limits. The arsenic content in the maize and bean samples, vegetables and those in the fish samples ranged from 5.21 to $7.03 \mu \mathrm{g} / 100 \mathrm{~g}, 2.89$ to $7.34 \mu \mathrm{g} / 100 \mathrm{~g}$, and 4.31 to $7.66 \mu \mathrm{g} / 100 \mathrm{~g}$, respectively. This range was also within the safe WHO limits, and therefore does not pose a significant risk for arsenic poisoning to the consumers. However, there were significant differences $(\mathrm{p}<0.05)$ in the arsenic content in water and soil samples due to geographical location. For the food samples, there was significant difference $(p<0.05)$ in the arsenic content among the different foods analyzed. It is recommended that continuous monitoring of arsenic levels of water, soil and foods be put in place since there is likely to be seasonal variations in their levels.

\section{CONFLICT OF INTEREST}

None declared.

\section{ACKNOWLEDGEMENT}

The authors are very grateful to the Inter-University Council of Eastern Africa through the Lake Victoria Research (ViCRES) for supporting the study and meeting the publication costs of this manuscript.

\section{REFERENCES}

[1] World Health Organization (WHO). "Trace Elements in Human Nutrition and Health”. World Health Organisation, Geneva. 1995.

[2] International Atomic Energy Agency (IAEA). "Sampling, storage and sample preparation procedures for X- Ray fluorescence analysis of environmental samples". IAEA, 2004. 
[3] L. Jarup, "Hazards of heavy metal contamination". Brazil Med. Bull., vol. 68, pp. 167-182, 2003.

[4] A. Hall, " Chronic arsenic poisoning“. Toxicol. Lett., vol. 128, pp. $69-72,2002$.

[5] World Health Organization (WHO). "Joint FAO/WHO Food Standards Programme". Codex Committee on Food Additives and Contaminants. Thirty-second session. Denmark, 1999.

[6] F.Iqbal, N. Raza, M. Ali and M. Athar. "Contamination of Kallar Kahar Lake by inorganic elements and heavy metals and their temporal variations", J. App. Sci. Environ. Manag., vol. 10(2), pp. 9598, 2006.

[7] Official Methods of Analysis of the Association of Analytical Chemists (AOAC). 14 $4^{\text {th }}$ ed. AOAC Washington DC: USA, 1984.

[8] M. Turzen, "Determination of heavy metals in soil, mushroom and plant samples by atomic absorption spectroscopy". Available at: www.sciencedirect.com/science [Accessed on $10^{\text {th }}$ September 2010].

[9] I. Turkebul, M. Elmastas, and M. Turzen, "Determination of iron, copper, manganese, zinc, lead and cadmium in mushroom samples from Tokat," Turkey. Food Chem., vol. 84(3), pp. 389-392, 2004.

[10] World Health Organization (WHO), "Sixty-seventh report of the Joint FAO/WHO Expert Committee on Food Additives". WHO Technical Report Series 940. WHO, 2006.

[11] D. R. Osborne, and P. Voogt, The analysis of Nutrients in Food. Academic Press: London, England, 1978.

[12] J. Schwartz, "Beyond LOEL's p values, and vote counting: methods for looking at shapes and strengths of associations". Neurotoxicity, vol. 14, pp. 237-46, 1993

[13] World Health Organization (WHO), "Evaluation of certain food additives and contaminants", Forty-first report of the joint FAO/WHO Expert committee on food additives. WHO Technical report Series, no. 837. WHO, Geneva, 1993.

[14] World Health Organization (WHO), "Safety evaluation of certain food additives and contaminants", International Programme on Chemical Safety. WHO Food Additive Series 52. WHO, 2004.

[15] H. L. Nguyen, M. Leermakers, M. Elskens, F.D. Ridder, T.H. Doan and W. Baeyens, "Correlations, partitioning and bioaccumulation of heavy metals between different compartments of Lake Balton," Sci. Total Environ., vol. 341, pp. 211-226, 2005.

[16] W. Baeyens, K. Parmentier, L. Goeyens, G. Ducastel, M. De Gieter and $\mathrm{M}$. Leermakers, "Biogeochemical behaviour of $\mathrm{Cd}, \mathrm{Cu}, \mathrm{Pb}$ and $\mathrm{Zn}$ in Scheldt estuary: results of the 1995 surveys," Hydrobiol., vol. 366, pp. 45-62, 1998.
[17] E. Weir, "Arsenic and drinking water,", Canad. Med. Assoc. J., vol. 166, pp. 69-72, 2002.

[18] A. L.O. Silva, P.R.G. Barrocas, S.C. Jacob and J.C. Moreira, "Dietary intake and health effects of selected toxic elements", Braz. J. Plant Physiol., vol. 17, pp. 79-93, 2005.

[19] M.A. Ali, A.B.M Badruzzaman, M.A. Jalil, M. D. Hossain, M.F. Ahmed and A.A.Masud,"Arsenic in plant and soil environment of Bangladesh," In: Feroze AM, Ashraf AM, Adeel Z, Eds. Fate of arsenic in the environment. Dhaka: Bangladesh Univ. Eng. Technol., 2003, pp. 85-112.

[20] N.W. Ghelberg, E. Bodor, and Z. Piersica, Hair analysis- a screening test for heavy metal burden of the organism, International Meeting of the Israeli Ecology Society: Rehovot, pp. 577-84, 1983.

[21] S.M.E. Huq, "Arsenic contamination in food chain: Transfer of arsenic into food materials through ground water irrigation," $J$. Health, Popul. Nutr., vol. 24(3), pp. 305-316, 2006.

[22] L. Jarup, L, "Hazards of heavy metal contamination". Brazil. Med. Bull., vol. 68, pp. 167-182, 2004.

[23] N. Leelhaphunt, S. Chuenta, M. Punnachaiya, W. Chuenta, and S. Nouchpramool S, "Analysis of toxic elements in food and drinking water in Thailand by neutron activation analysis. Nuclear techniques for toxic elements in foodstuffs," Report of International Atomic Energy Agency (IAEA). Coordination Research Program. pp. 215-267. IAEA: Vienna, 1994.

[24] A.O. Makokha, L.R. Mghweno, H.S. Magoha, A. Nakajugo and J.M. Wekesa, "Environmental lead pollution and contamination in food around Lake Victoria, Kisumu, Kenya," African J. Environ. Sci. Technol., vol. 2(10), pp. 349-353, 2008

[25] R. Naidu. "Geogenic Arsenic and associated toxicity problems in the groundwater soil-plant-animal-human continuum, Expert Group Meeting on Arsenic, Nutrition and Food Chain". UNICEF, Bangladesh Country Office, Dhaka. 2001

[26] M.J. Abedin, M.S. Crasser, A.A. Emhart, J. Feldman and J. CotterHowells, "Arsenic accumulation and metabolism in rice (Orzo sativa L.)," Environ. Sci. Technol., vol. 36, pp. 962-8, 2002.

[27] H. Hironaka and S.A. Ahmad, "Arsenic concentration of rice in Bangladesh," In: Feroze AM, Ashraf AM, Adeel Z, Eds. Fate of arsenic in the environment. Dhaka: Bangladesh University of Engineering and Technol., pp. 123-30, Dhaka, 2003.

[28] Z. Alam, and Rahman M, "Accumulation of arsenic in rice plant from arsenic contaminated irrigation water and effect on nutrient content," In: Feroze A.M., Ashraf A.M., Adeel, Z. Eds., Fate of arsenic in the environment. Dhaka: Bangladesh University of Engineering and Technology, 131-5, 2003.

(C) Makokha et al.; Licensee Bentham Open.

This is an open access article licensed under the terms of the Creative Commons Attribution Non-Commercial License (http://creativecommons.org/licenses/by-nc/3.0/g) which permits unrestricted, non-commercial use, distribution and reproduction in any medium, provided the work is properly cited. 